\title{
Botulinum neurotoxin formulations: overcoming the confusion
}

\section{Souphiyeh Samizadeh' \\ Koenraad De Boulle ${ }^{2}$}

'Great British Academy of Aesthetic Medicine, London, UK; ${ }^{2}$ Aalst

Dermatology Clinic, Aalst, Belgium

Video abstract

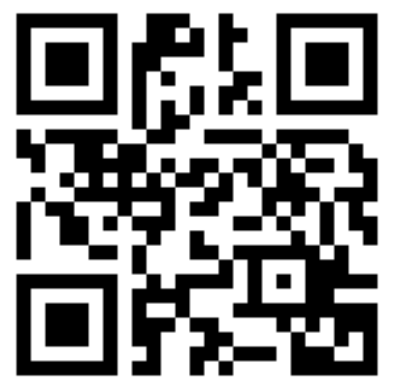

Point your SmartPhone at the code above. If you have a QR code reader the video abstract will appear. Or use: http://youtu.be/HyPuOn_ONXO
Correspondence: Souphiyeh Samizadeh Great British Academy of Aesthetic Medicine, London, England, W4 2HA Tel +4420328727I7

Email info@baamed.co.uk
This article was published in the following Dove Press journal: Clinical, Cosmetic and Investigational Dermatology

\begin{abstract}
Botulinum toxin A is produced by anaerobic spore-forming bacteria and is used for various therapeutic and cosmetic purposes. Botulinum toxin A injections are the most popular nonsurgical procedure worldwide. Despite an increased demand for botulinum toxin A injections, the clinical pharmacology and differences in formulation of commonly available products are poorly understood. The various products available in the market are unique and vary in terms of units, chemical properties, biological activities, and weight, and are therefore not interchangeable. For safe clinical practice and to achieve optimal results, the practitioners need to understand the clinical issues of potency, conversion ratio, and safety issues (toxin spread and immunogenicity). In this paper, the basic clinical pharmacology of botulinum toxin $\mathrm{A}$ and differences between onabotulinum toxin $\mathrm{A}$, abobotulinum toxin $\mathrm{A}$, and incobotulinum toxin $\mathrm{A}$ are discussed.
\end{abstract}

Keywords: botulinum toxin, botulinum neurotoxin, moiety, protein complexes

\section{Introduction}

Botulinum toxin is produced by the anaerobic spore-forming bacteria of the genus Clostridium. It consists of a complex mixture of proteins containing botulinum neurotoxin (BoNT) and several nontoxic proteins. BoNTs are the most potent toxins known to mankind and can cause botulism. ${ }^{1}$ There are eight distinct BoNT serotypes (A-G) produced by different strains of Clostridium botulinum. ${ }^{2,3}$ The human nervous system is susceptible to BoNT-A, B, C, E, F, and G and unaffected by D. ${ }^{1,4-6}$ Recent advances have resulted in the discovery of genes encoding for many new BoNTs that may be grouped within an existing serotype but with various amino acid sequences. In addition, there are some chimeric BoNTs, for example, BoNT-DC. All serotypes have a similar molecular architecture. ${ }^{7}$ Only serotypes A and B are widely used for clinical applications as their effect is longer lasting than other serotypes. ${ }^{8}$ BoNTs differ with each other in terms of protein size of the neurotoxin complex, the amount of neurotoxin in the activated or nicked form, potency, and intracellular protein target. These properties vary among different preparations of the same serotype. ${ }^{9}$

BoNTs enter peripheral cholinergic nerve terminals where they cleave one or two of the three core proteins of the neuroexocytosis apparatus. This results in temporary and reversible inhibition of neurotransmitter release. ${ }^{10}$ Paresis occurs $2-5$ days after injection, reaches its maximal point at 5-6 weeks, and lasts for approximately 2-3 months. ${ }^{8,11}$ BoNT seems to be preferentially taken up by hyperactive nerve terminals. Nerve stimulation has been reported to increase the rapidity of BoNT poisoning. ${ }^{10}$ 
The recovery of muscle contraction happens gradually and in two stages: ${ }^{12}$

- Stage 1 involves the return of exocytosis: reappearance of vesicle turnover in the sprouts and functional recovery of the neurones

- Stage 2 involves the return of the vesicle turnover in the original terminals and regression of the sprouts.

The initial functional recovery is mediated by the terminal sprouts followed by reestablishment of the original terminals. ${ }^{12}$ Rogozhin et al reported that the new synaptic contacts play a relatively minor role in functional recovery. The original neuromuscular junction is reported to play a more significant role than previously thought. ${ }^{13}$

The specificity of action of BoNT has made this neurotoxin a useful therapeutic agent. The range of clinical application of BoNT is vast and fast growing with some of the clinical uses summarized in Table 1. BoNT-A is extensively used for aesthetic purposes worldwide and has been shown to have direct analgesic effects, mediated through blockade of substance $\mathrm{P}$, glutamate, and calcitonin gene-related peptide. ${ }^{11}$ The basis of popular use of BoNT is its potency, neurospecificity, and complete reversibility. ${ }^{10}$

\section{BoNT-A formulations}

There are several BoNT-A-containing products available on the market, and they vary in terms of the following: ${ }^{1,8,14}$

- Composition

- Amount of neurotoxin

- Units

- Toxin complex size

- Molecular weight

- Chemical properties

- Biological activity

- $\mathrm{pH}$

- Storage

- Risk of antigenicity

- Indication of use

- Geographic distribution.

The three botulinum toxin formulations that have been approved by the US Food and Drug Administration and are well known in the Western hemisphere are as follows:

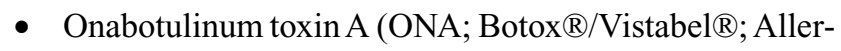
gan Inc., Dublin, Ireland)

- Abobotulinum toxin A (ABO; Dysport $\AA / A z z a l u r e ®$; Ipsen, Paris, France/Galderma, Lausanne, Switzerland)
- Incobotulinum toxin A (INCO; Xeomin $\AA /$ Bocouture $\AA$, NT 201; Merz Pharmaceuticals GmbH, Frankfurt, Germany)

Each of these products are approved for various and limited indications in various countries. However, companies are evolving, and approved indications in various countries are constantly changing. Despite having similar efficacies, there is an ongoing debate regarding the comparability of these various preparations. ${ }^{3}$ Each of these neurotoxins is formulated differently, has a different manufacturing process, and demonstrates unique characteristics, and subsequently, these products are not interchangeable (Table 2). ${ }^{15}$ For safe clinical practice and achieving optimal results for a given indication, the practitioners need to understand the clinical issues of potency, conversion ratio, and safety (toxin spread and immunogenicity). A correct and optimal treatment plan and procedure requires an in-depth knowledge of the product(s) used, anatomy, and injection technique. ${ }^{8}$

The effect of BoNT depends on the administered location, concentration, and volume which are in turn relative to the location, depth, and size of the target muscle. ${ }^{1}$ Numerous published studies compare the characteristics of these products. However, when reviewing the literature on efficacy, diffusion, and spread of various products and in comparison to each other, it is important to take into consideration all the possible contributing factors including the following: ${ }^{16}$

- Intrinsic properties of the toxins available

○ Protein load

- Muscle selection

- Muscle activity pattern

- Muscle architecture

- Fascial planes

- Injection technique

○ Dilutions

- Volumes

$\circ$ Doses.

\section{Molecular architecture}

BoNT-A is synthesized as macromolecular protein complexes in nature. ${ }^{9}$ The progenitor toxins are known as protein complexes and consist of nontoxic accessory proteins (NAPs). The BoNT-A protein has a molecular weight of $150 \mathrm{kDa}$, and the NAP is associated to this active neurotoxin. The NAP composition of different products varies. ${ }^{3}$

There is amino acid sequence variability and immunogenic differences between various serotypes. However, they 


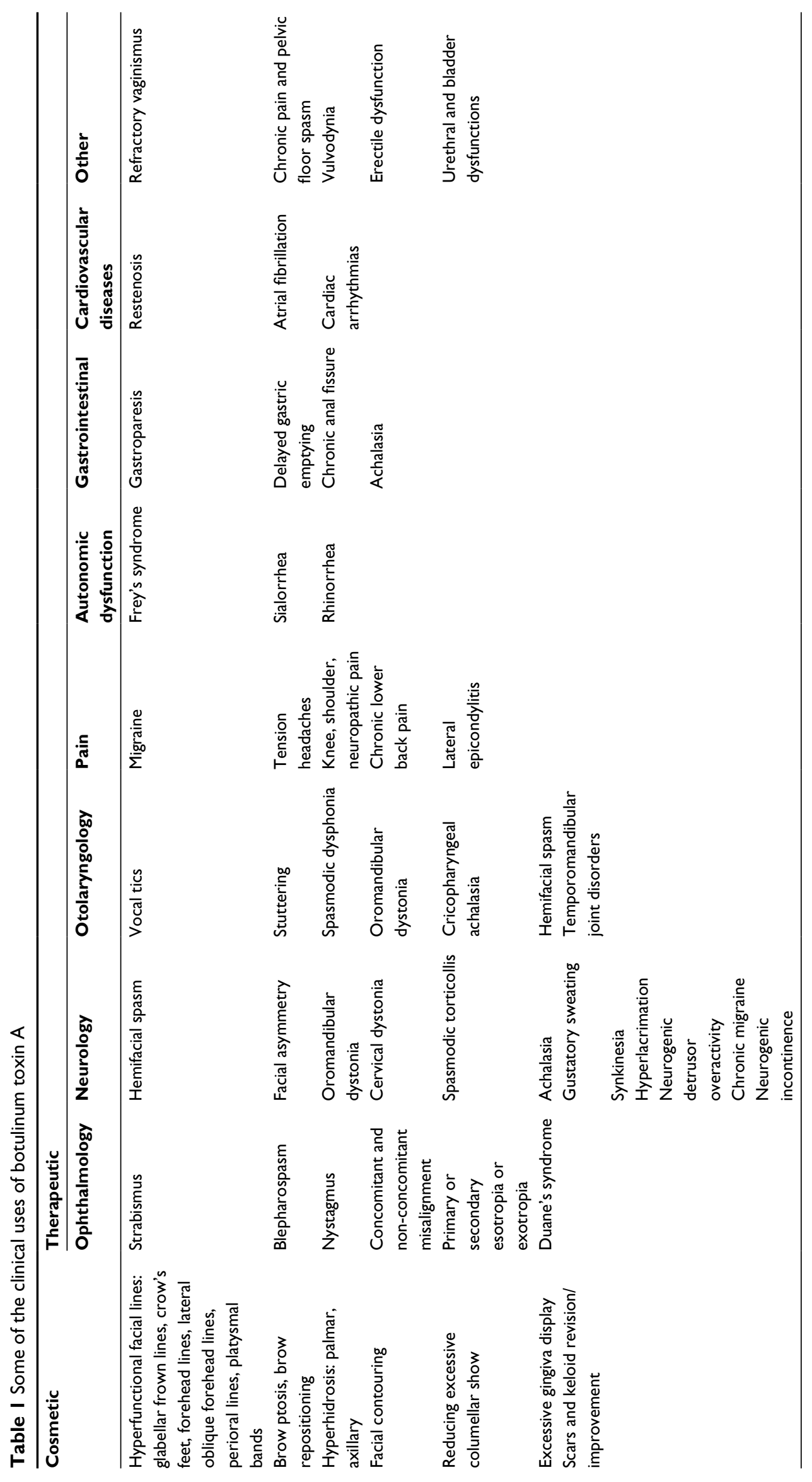




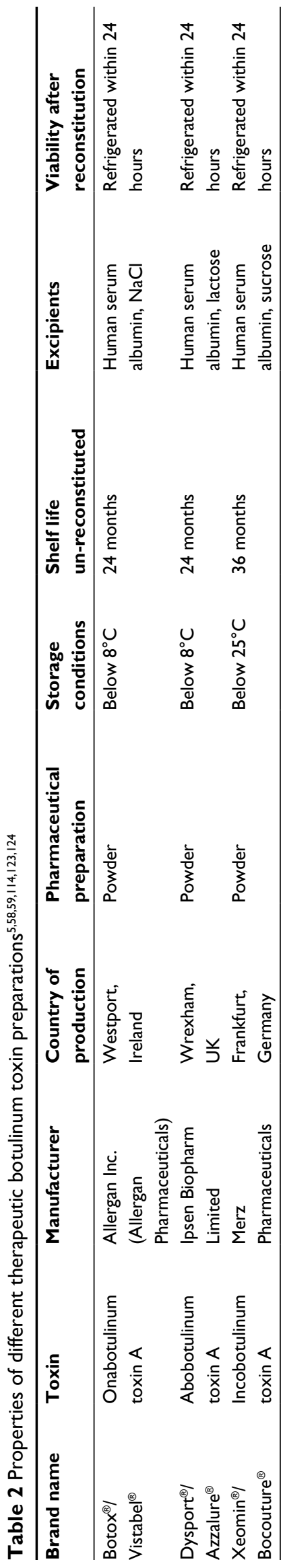

all have a similar molecular structure and architecture. The BoNTs are produced as a single-chain polypeptide ( $150 \mathrm{kDa})$ that is inactive. Proteases nick the polypeptide chain resulting in a toxin that is pharmacologically active and consists of two chains: a heavy chain $(100 \mathrm{kDa})$ and a light chain $(50 \mathrm{kDa})$ connected together by a disulfide bond. In addition, there are noncovalent interactions, and the $\mathrm{N}$ terminus of the heavy chain encircles the globular light domain., ${ }^{7,17}$ The heavy chain has two $50 \mathrm{kDa}$ domains with two terminal parts, the amino- and the carboxy-terminal parts. ${ }^{7}$ Each of these chains has different functions in the mechanism of action of the neurotoxin (Figure 1). ${ }^{19}$ The single disulfide bridge and its integrity play an integral role in biological activity of BoNT, making it highly fragile to various environmental variations and influences. ${ }^{20}$

\section{Composition}

The therapeutic preparations of botulinum toxin consist of the following (Figure 2): $:$,20

- BoNT

- NAPs

- Excipients (lactose, sucrose, gelatin, dextran or serum albumin [for stabilization], buffer systems [for $\mathrm{pH}$ calibration]).

It has been reported that in all mentioned products (ONA, $\mathrm{ABO}, \mathrm{INCO}$ ), the neurotoxin is derived from the identical Hall strain of C. botulinum type A..$^{21,22}$ However, there is evidence that Hall strains are different to each other, and the strain information for the products apart from ONA (Allergan Botox $\left.{ }^{\circledR}\right)$ is unknown. ${ }^{23-25}$

The molecular weight of the BoNT-A progenitor toxins varies between 300 and $900 \mathrm{kDa}$. This weight variation depends on the composition of NAPs and the manufacturing process. ${ }^{20} \mathrm{INCO}$ contains only the $150 \mathrm{kDa}$ neurotoxin and does not include complexing proteins..$^{20,21}$ The $150 \mathrm{kDa}$ neurotoxin is part of a complex with other proteins (complexing

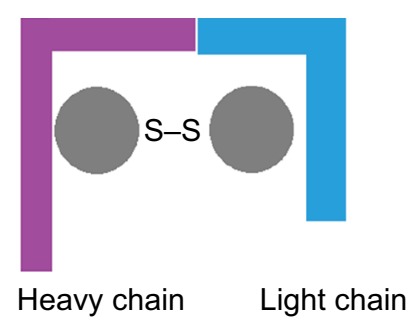

Figure I Botulinum neurotoxin consists of two amino acid chains connected by a disulfide bridge: a heavy amino acid chain with a molecular weight of $100 \mathrm{kDa}$ and a light amino acid chain with a molecular weight of $50 \mathrm{kDa} .^{20}$ 


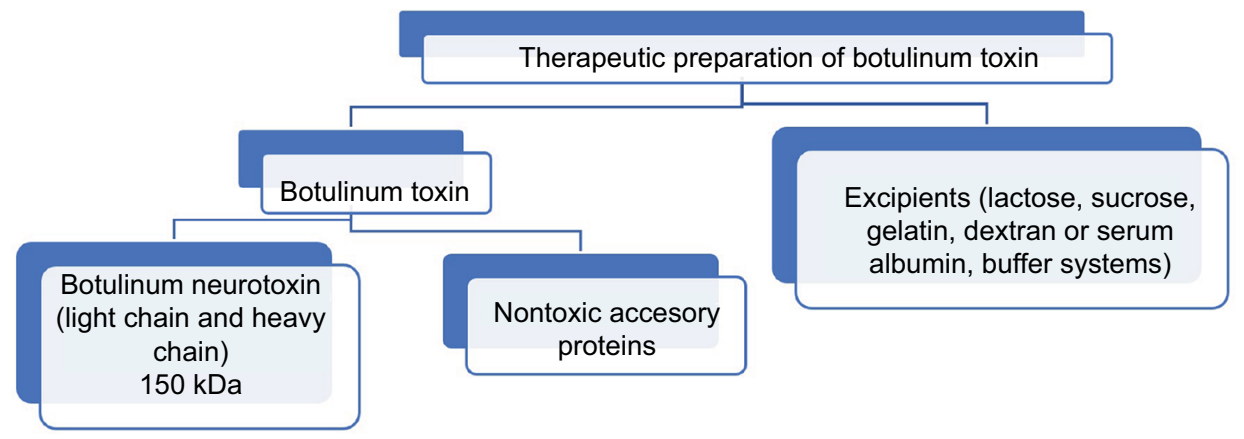

Figure 2 Simplified contents of therapeutic botulinum toxin preparations.

proteins) in ONA and ABO ${ }^{21}$ ONA is composed of a $900 \mathrm{kDa}$ complex, ${ }^{26}$ and the size of the ABO complex is unknown. ${ }^{27}$

After dilution, drying, and reconstitution of the product, the neurotoxin rapidly dissociates from the complexing proteins. As such, it has been debated that molecular weight (protein complex size) does not influence the biological activity and pharmacological properties of BoNT. ${ }^{28,29}$ Complexing proteins do not contribute toward diffusion properties, seem not to contribute to the therapeutic effect, and are not required for the stabilization of the neurotoxin in the pharmaceutical formulation. ${ }^{30}$ However, more studies are required to assess if the complexing proteins increase formation of antibodies against botulinum toxin type $\mathrm{A}$.

\section{Mode of action, pharmacology, and clinical assessment}

The mechanism of action of BoNT on the nerve terminals can be summarized into five main steps: 1) binding of the BoNT to the peripheral cholinergic nerve terminals with high affinity and specificity, 2) internalization of the BoNT, 3) translocation (the light chain is translocated across the vesicle membrane), 4) release of the light chain and dissociation of the disulfide bond, and 5) cleavage of the SNARE proteins (the light chain cleaves SNAP-25) resulting in blockade of neurotransmitter release and therefore neuroparalysis., ${ }^{27,31}$ This inhibits synaptic exocytosis and incapacitates neural transmission resulting in blockage of the release of acetylcholine at the neuromuscular junction and hence blocking the muscle contraction. ${ }^{32}$

BoNT-elicited inhibition of neuroexocytosis depends on various factors including the toxin serotype, dose used, type of cholinergic nerve terminal affected, and also the animal species. ${ }^{10,33}$ Size of the denervation field of BoNT is determined by dose and volume of the solution injection. Clinical observation, wrinkle severity scales, area of anhidrotic effect, and electromyography evaluations are some of the methods used to examine the size of denervation field of different products. However, when evaluating such studies, the difference between the potency and dose equivalences of different preparations should be taken into consideration. Shaari and Sanders reported that in comparison to volume, the dose injected was a stronger predictor of area of paralysis. ${ }^{34}$ The proximity of the injections to the motor end plates plays a key role. ${ }^{34}$

\section{Direct and indirect effects}

BoNT has been reported to have direct and indirect effects. The direct effects include inhibition or blockage of the cholinergic neuromuscular or the cholinergic autonomic innervation of exocrine glands and smooth muscles. ${ }^{20}$ Presence of BoNT in the peripheral blood at measurable levels, after intramuscular or intradermal injection at the recommended doses, is not expected and has not been reported. ${ }^{8}$ The indirect effects include effects on the central nervous system such as the following: ${ }^{11}$

- Reflex inhibition

- Normalization of reciprocal inhibition

- Intracortical inhibition

- Somatosensory evoked potentials.

The long-distance effects of BoNT do not happen by passive spread, but by an active retroaxonal transport. ${ }^{35,36}$ BoNT-A can retrotransport to the central nervous system. This was studied by tracing the cleavage of the SNARE proteins within the central nervous system neurons post peripheral injection of BoNT. ${ }^{35,37-39}$ Retrograde transport of BoNT-A has been reported via sensory neurons. ${ }^{36}$ There is evidence for antinociceptive activity of BoNT-A; however, no other associated symptoms due to BoNT acting within the central nervous system post peripheral injection have been reported. ${ }^{39,40}$ The direct and indirect effects are advantageous depending on the purpose of administration and the injection 
target. For example, the central action can contribute to functional improvements in spastic gait and can be beneficial in pain management. ${ }^{39}$

\section{Duration of action}

The duration of persistence of the clinical results (eg, elimination of the wrinkles) is one of the key measures for BoNT efficacy. This has been reported to have significant influence on patient satisfaction in cosmetic patients and may be related to individual patient's genetics and the target muscle (mass, size, thickness, and depth below the skin and structure). ${ }^{41,42}$ The specific administered dose of BoNT influences the efficacy and duration of effect. ${ }^{43}$

The methods for assessment of onset of action in the clinic are not universal or fully validated and rely on reduced or diminished muscle activity assessed by the practitioner or reported by the patient. The onset of effect is different for different formulations. There is lack of consensus in the literature on the reason for this. ${ }^{44}$

Studying and understanding the onset of action requires further comprehension and needs to be clearly defined. Onset of action of BoNT could be explained on a molecular level or as the presentation of the molecular events that take place (the biological effects). On a molecular level, the onset of action happens as soon as BoNT is injected into the muscle: ${ }^{45,46}$

- Resides in the extracellular space (toxin uptake only takes place by the nerve terminals at the endplate)

- In the muscle for a short time (minutes or at most a few hours) and the uptake is rapid

- Binds to the surface of plasma membranes

- Receptor-mediated endocytosis

- $\mathrm{pH}$-induced translocation across the endosome membrane

- In the presynaptic terminal, cleavage of the SNARE proteins (SNAP-25) - essential for exocytosis

- Blockade of transmitter release

- Paralysis.

As such, the time taken for the toxin to be taken up and the time for the clinical response to become evident differ considerably. ${ }^{45}$

When discussing the time interval of onset to response, it is once again important to explain what is meant by "response":

- Partial elimination of the lines and wrinkles/reduced lines and wrinkles

- Complete elimination of the lines and wrinkles

- Agonist muscle(s) action affected

- Antagonist muscle action affected
- The desired balance between the agonist and antagonist muscles achieved.

The mentioned events happen at different times and may not be fully achieved by the time patients are reviewed after injections which is normally in 7-14 days after injections.

Paresis occurs after 2-5 days post injection of BoNT into a striate muscle. This effect lasts 2-3 months before wearing off gradually as the original nerve terminals recover. ${ }^{11,13}$ Three studies conducted with ONA reported mean or median duration of effect for various doses to be approximately 4.5 months. ${ }^{47}$ Examination of the literature has shown that patients treated with BoNT-A for aesthetic purposes can expect their results to last at least 3 months. However, the results can last 4-5 months depending on the area treated, the dose, and the formulation used. ${ }^{48}$ Although the mechanism is not fully understood, the results may last longer for some patients, especially after repeated treatment. ${ }^{49-51}$ Muscle atrophy and reduced number of BoNT-A targets available are thought to be related to the prolonged effect. ${ }^{44}$ Dolly and Aoki reported that there is no atrophy of the nerve endings upon blockade of neurotransmitter. ${ }^{52}$ Rogozhin et al reported that repeated exposure to BoNT-A results in delayed restoration of neuromuscular transmission back to normal. In addition, it results in profound abnormalities in the structure of the neuromuscular junction and the intramuscular nerve. ${ }^{13}$

In a randomized, double-blind study, Rappl et al reported that in female subjects, the onset of treatment effect happened earlier and the treatment effect duration was longer when a similar dose was applied. In their study, the onset of treatment effect was seen earlier in both sexes for INCO compared to ONA and ABO. The duration of treatment effect (the time taken for the glabellar muscle activity to return to the baseline level) was reported to be longer for INCO in comparison to the other two products. ${ }^{53}$ Glogau et al studied duration of effect of aesthetic treatments with BoNT using data obtained from four Phase III clinical trials with similar designs and a total of 625 subjects treated with ONA. They reported that there was sustained clinical effect for 4 months (in more than $50 \%$ of subjects) after treatment of glabellar lines with 20 units of ONA. ${ }^{54}$

Poor response to the treatment could be due to insufficient or incorrect dosing, errors in drug handling during preparation or storage or administration, and anatomical variations. ${ }^{44}$

\section{Dose-effect correlation}

The extent of provoked paresis is correlated to the amount of BoNT administered. Dressler and Rothwell studied the relationship between the dose of BoNT-A and induced reduction 
of the maximal electromyographic amplitude in the sternocleidomastoid muscle. They reported a dose-effect relationship. ${ }^{55}$ In a prospective multicenter placebo-controlled double-blind dose-ranging study, Poewe et al reported that higher doses of $\mathrm{ABO}$ resulted in greater magnitude and duration of improvement in patients with rotational torticollis. They recommended lower starting does as higher doses used resulted in significantly more adverse events. ${ }^{56}$ Dressler et al reported that relatively low BoNT doses produce substantial paresis. ${ }^{11}$ The dose-effect correlation can be used for optimization of BoNT treatment. ${ }^{11,55}$

\section{Dose-duration correlation}

Duration of effect of treatments is an important factor as it influences treatment intervals and determines patient satisfaction to some extent. ${ }^{57}$ When lower doses of BoNT are used, the duration of its action is correlated to the amount injected. However, the duration of action is thought to saturate on approximately 3 months when higher BoNT doses are used. ${ }^{11}$ Carruthers and Carruthers, in a prospective, double-blind, randomized, parallel-group, dose-ranging study, reported that the higher doses of BoNT were more effective (duration, peak response rate, improvement from baseline) in reducing glabellar lines in men. A dose-dependent increase was reported in the duration of effect, as well as the response rate at maximum frown with no increase in incidence of adverse effects. They also reported that their participants reported a dose-dependent reduction in frowning, and enhanced feelings of attractiveness, confidence, and satisfaction. ${ }^{43}$ In another study, Carruthers et al reported that lower units of BoNT-A (10 units) were less effective than higher doses in treating glabellar rhytids and the relapse rate was significantly higher at 4 months. ${ }^{58}$

\section{Muscle atrophy}

BoNT induces paresis of striate muscle which in turn produces muscle atrophy and reduction of the diameter of the target muscle. ${ }^{11}$ Muscle atrophy caused by BoNT injection can be the aim of the treatment and hence a desirable effect or an unintended and undesirable effect. Injection of masseter muscles to reduce the appearance of square lower face and for facial contouring is highly prevalent is Asia. ${ }^{59-61}$ Evident reduction in size of masseter muscles has been reported in as little as 2 weeks, with maximal reduction in approximately 6-8 weeks. ${ }^{62}$ The "hourglass deformity" due to temporalis atrophy caused by repeated treatment of BoNT-A was described by Guyuron et al in patients treated for migraine and reported to resolve in all patients several months after recovery of muscle function. ${ }^{63}$

\section{Potency}

The biological potency of BoNT formulations is based on the median lethal dose of the neurotoxin after intraperitoneal injection in female Swiss-Webster mice and is also known as median lethal dose (LD50) assay. Potency used to be explained by the quantity of toxin required to achieve a median lethal dose (LD50) unit. Therefore, 1 unit of toxin (1 mouse LD50) is the dose of toxin or neurotoxin that can kill $50 \%$ of a group of mice. During the production process, potency and stability testings are required at several stages, and at the final stage, a large number of animals are used. A cell-based potency assay is a new modality for assessment of units in BoNTA and has resulted in elimination of the LD50 assay in some laboratories. ${ }^{64}$ This method uses a specific cell line and can carry out evaluation of all four phases of botulinum toxin action (binding, internalization, translocation, and SNAP-25 cleavage). This method is superior as it reduces the need for animal testing, has been successfully cross-validated with the LD50 assay, and is appropriate to be used in a high-capacity and in a highly quality-controlled environment. ${ }^{8}$ In addition, it has been reported to be more accurate and reproducible. ${ }^{65}$ Allergan Inc. (produces ONA) has developed a cell-based potency assay for potency testing, which has received regulatory approval. ${ }^{65,66}$ In 2014, Merz Pharmaceuticals $\mathrm{GmbH}$ (produces INCO) also completed the validation of cell culture-based assay for INCO. ${ }^{67}$

The dose of product for treating patients is determined by each manufacturer's result of LD50 or cell-based potency assay. This is dependent on multiple variables including mouse strain, sex, age, volume, route of injection, time of examination after injection, delivery vehicle, and reconstituting buffer. These are not standardized across manufacturers. ${ }^{3}$ The standards and in-house diluents for these LD50 potency assays are different for each manufacturer, and therefore, the unit of measurement for the three commercially available BoNT-A preparations is proprietary to each manufacturer. As such, the direct comparisons of potency between products are not valid. ${ }^{23,29,67-70}$ The specific potency explained as the potency per unit weight of toxin protein means the level of protein administered per injection. ${ }^{25}$

The toxin moiety (the $150 \mathrm{kDa}$ neurotoxin) is the same in all abovementioned pharmaceutical preparations. Potency of a product depends on the amount of active toxin available. ${ }^{3}$ In order for the neurotoxin to be activated, the single-chain 
$150 \mathrm{kDa}$ neurotoxin must be cleaved into a dichain molecule which must dissociate from the NAPs. Apart from INCO, all commercially available formulations are composed of the 150 kDa neurotoxin with NAPs. ${ }^{3}$ The molecular weight of the BoNT-A progenitor toxins varies (300-900 kDa) depending on the composition of NAPs and the manufacturing process. ${ }^{20}$ From a clinical point of view, this means that the potency and therapeutic profiles can be affected by different forms of the complex despite the same active molecule. ${ }^{3}$

\section{Reconstitution}

All the above products are in powder form and need to be reconstituted prior to application. There is debate with regard to reconstitution with normal saline with no preservatives and preserved $(0.9 \%$ benzyl alcohol) saline. The manufacturer's suggested diluent is normal saline with no preservatives. Several authors have reported equivalent clinical effectiveness with BoNT-A diluted with preserved saline. However, there is a debate on whether the preservatives in the saline deactivate the toxin partially. ${ }^{71,72}$ Alam et al, in a double-blind, randomized controlled trial, reported that preserved saline containing benzyl alcohol used in reconstitution of ONA did not affect its potency or clinical outcome and made the injections less painful. ${ }^{73}$ This was confirmed by two other studies. $^{74,75}$

It has been traditionally believed that shaking, bubbling, and storing the vial for a long period of time reduces the efficacy of BoNT. However, a few clinical studies have contradicted this. Trindade De Almeida et al compared muscle paralysis in a split-face study. They injected gently reconstituted ONA without foam formation on one side of the face and rapidly reconstituted ONA with foam formation "with as many bubbles as possible" on the other side. They reported that the potency and the short- or long-term effects of the product were not affected by foaming during the reconstitution process. ${ }^{76}$ This was supported by a prospective, doubleblinded, randomized study carried out by Kazim and Black who used a Vortex Touch Model 232 at maximum speed for 30 seconds (vigorous reconstitution of ONA). ${ }^{77}$ The 2004 consensus panel has reported that the fragility of BoNT-A is not as previously reported. ${ }^{78}$ It is now understood that a lot of the precautions, mainly recommended by the manufacturers, are "too restrictive". Studies and the literature show that BoNT may be less fragile and more resistant to degradation than previously thought. ${ }^{79}$

It is paramount to remember that suboptimal reconstitution of BoNT preparations can reduce or diminish their efficacy. ${ }^{80,81}$ Inaccurate reconstitution could result in inaccuracy of actual units injected and therefore compromised treatment. ${ }^{80}$

Niamtu has shown that conventional methods of reconstitution can result in an average loss of 5 units. ${ }^{81}$ The size of needle plays a key role in loss of volume/units of product. A $30 \mathrm{G}$ needle results in loss of $0.03 \mathrm{~mL}$ of the product in the dead space. Use of no dead space needles could ensure minimal to no loss of solution. In addition, new devices/ syringes (eg, 3Dose Vlow Medical) with a triangular plunger help reduce/eliminate loss of solution and are easy to use and read number of units for different dilutions.

Use of fixed needles to syringes is less advisable. Upon drawing the product into the syringe, the needle goes through the silicone rubber stopper; hence, the needle becomes blunt, injections might be more painful, and there will be molecules of silicone in the needle. The silicone molecules will end up as foreign bodies in the muscle or skin. In addition, some insulin syringes have a silicone-coated needle. ${ }^{82}$ There has been reported cases of silicone granulomas and siliconoma with acupuncture needles and in diabetic patients due to repeated use of silicone oil-coated needles. ${ }^{83-85}$

\section{Dose equivalence}

Numerous studies have proved that all three mentioned products are effective. However, the practitioners need to understand the differences to be able to have a comparable clinical outcome. The debate on conversion ratios might have been emphasized, understandably, from a commercial point of view.

There are different amounts of the $150 \mathrm{kDa}$ toxin (and NAPs)/LD50 unit for different formulations of BoNT-A. Therefore, it is important for the clinicians to understand the equivalence ratio of the dose.

Clinical and preclinical analyses have demonstrated a clinical conversion ratio between ONA and INCO very close to $1: 1 .^{86,87}$ Prager et al reported that both these products had no statistically significant differences between them and showed high efficacy and good tolerability with a dose ratio of $1: 1 .^{88}$ Kane et al carried out a prospective, randomized, double-blinded, parallel-group study where a single treatment with INCO or ONA was carried out in 250 females. This was followed by a 4-month observational period. They reported clinical equivalence with similar safety and efficacy profiles and patient-reported outcomes. ${ }^{89}$

A number of studies have reported an ONA/INCO:ABO conversion factor of 1:3. However, this dose conversion is a topic of debate, and studies have reported ranges from 1:1 to as high as $1: 11 .^{90-93}$ The clinical and preclinical data available 
suggest a conversion ratio of 1:3 or 1:2.5. A higher conversion ratio may lead to the following:

- Excessive dose

- Increased incidence of adverse events

- Underdosing when switching ABO to ONA. ${ }^{3}$

Identical potency labeling between ONA and INCO allows easy exchange of these two drugs in clinical settings, and direct comparison of the efficacy, adverse effects, and costs. In summary, $\mathrm{ABO}$ and ONA have been reported to have nonparallel dose-response curves, and therefore differ in their relative potencies. ${ }^{94}$ The presumed clinical effect of 1 unit of BoNT is not interchangeable between formulations. ${ }^{95}$

\section{Toxin spread}

One of the factors contributing to remarkable safety record of BoNT therapy is the ability of the toxin to remain relatively localized at the site of injection. ${ }^{96-99}$ However, the effect of BoNT on areas away from the injection site is known as the toxin spread or field of effect. ${ }^{3}$ Toxin spread to unwanted areas can be undesirable as it may increase the risk of adverse effects and complications. This is of particular importance when treating the face with BoNT as the injection sites and target muscles are very close to untargeted muscles. Therefore, to minimize unwanted effects, it is important that the toxin does not spread and affect the adjacent untargeted muscles. For example, eyelid ptosis is a serious complication and can be devastating for patients who have BoNT injections to improve their appearance. It can happen post BoNT-A treatment in the periorbital area due to unintended spread of the product to the levator palpebrae superioris muscle and consequently its reduced activity. The levator palpebrae superioris muscle is adjacent to the target muscles and injection sites recommended for the treatment of the upper face rhytides using BoNT. These include the following (Figure 3):

- Procerus

- Depressor supercilii

- Corrugator

- Orbicularis oculi muscle..$^{22}$

There is a lack of consistency and much confusion about the terminology used regarding spread of the toxin (Table 3 ). Spread is an actual physical phenomenon that depends on several variables which are related to the injection done. It is a mechanistic effect and describes the physical movement of toxin from the original site of injection.
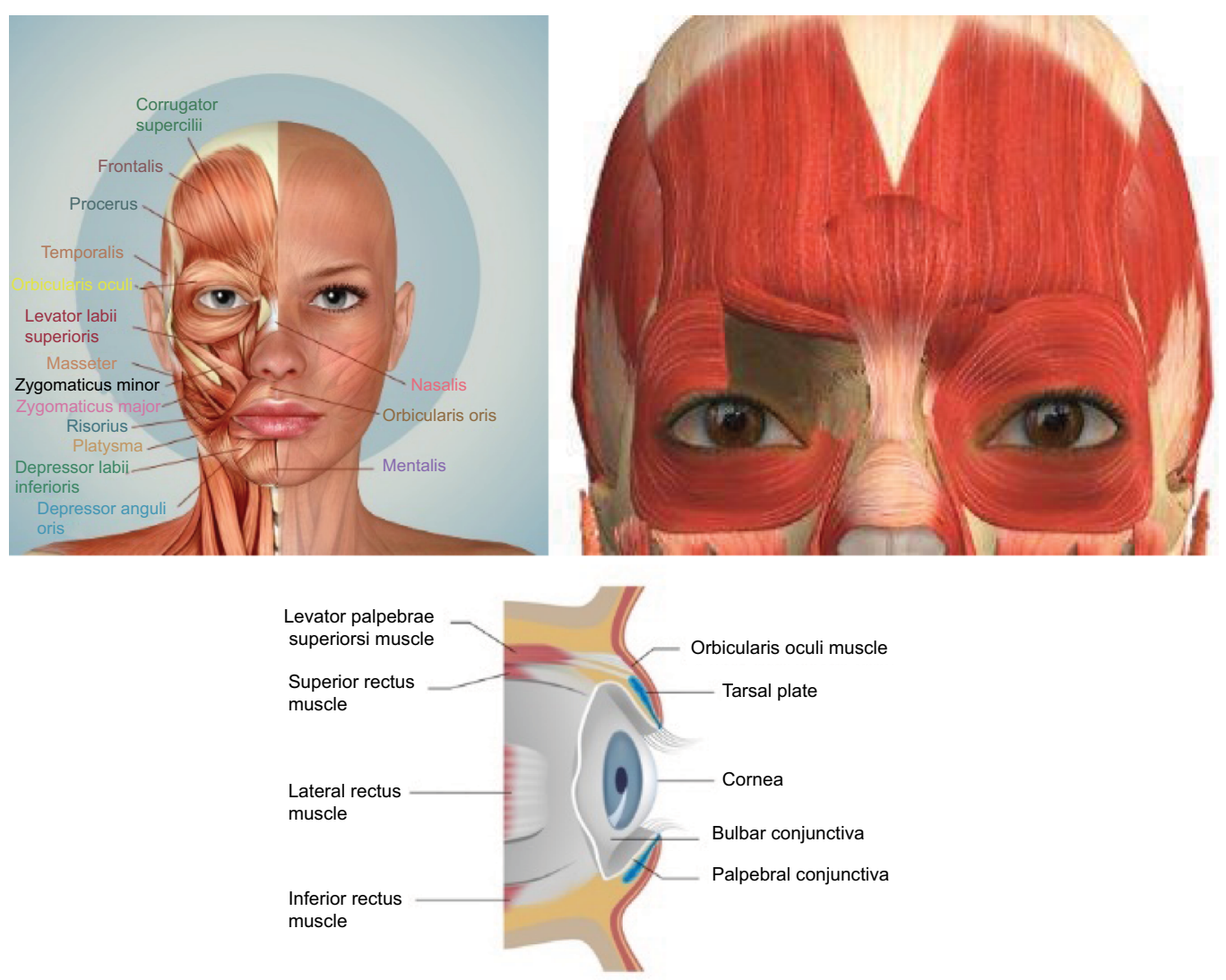

Figure 3 Glabellar complex muscles and position of levator palpebrae superioris muscle.

Note: Top right hand image provided courtesy of Allergan and top left hand image and bottom image acquired from Shutterstock. 
Table 3 Correct definitions to apply to botulinum toxin products for clinical administration

\begin{tabular}{ll}
\hline Term & Definition \\
\hline Spread & $\begin{array}{l}\text { Physical movement of toxin (caused by, for example, } \\
\text { volume of injection) }\end{array}$ \\
Fiffusion & $\begin{array}{l}\text { Fast and active process } \\
\text { Kinetic dispersion of toxin } \\
\text { Dispersion beyond the injection site (for example, } \\
\text { movement to receptors) }\end{array}$ \\
& $\begin{array}{l}\text { Slow and passive process } \\
\text { Migration }\end{array}$ \\
\hline
\end{tabular}

Diffusion is a passive phenomenon, and indicates the kinetic dispersion of the toxin outside its original injection site. ${ }^{27}$ The effect of dose on diffusion is thought to be significant. ${ }^{100}$ Arezzo exhibited a dose-dependent spread of biological activity to adjacent non-injected muscles. ${ }^{101} \mathrm{Car}-$ ruthers et al injected 30 units of ONA at different volumes used to reconstitute the vials for the treatment of glabellar lines. They reported that although there was no obvious relationship between the actual volume injected and response, higher dilutions can result in greater areas of "diffusion" and hence greater incidence of adverse effects. ${ }^{102} \mathrm{Hsu}$ et al reported in their prospective, randomized, controlled study that the area affected by the BoNT-A injection was $50 \%$ greater in the side with the larger volume with equivalent units of BoNT-A. ${ }^{103}$

Migration is the distal effect, or the "retrograde transport" phenomena via the nerves (neuroaxonal transport) or by blood (hematogenous transport). ${ }^{27,104}$ Two phenomena take place after injection and rapid dissociation of the complex: ${ }^{27}$

- Diffusion: passive function, occurs from a very high to low concentration

- Spread: physically driven, occurs active and fast.

Fick's law of diffusion explains diffusion related to molecular weight. As such, the spread of neurotoxin into adjacent tissue is reported to be slower with the high-molecular-weight complex in comparison to the lower-molecular weight or free neurotoxin. ${ }^{12,28}$ However, this is debatable, and further clinical studies are required. Kerscher et al have demonstrated that ONA with complexing proteins and a molecular weight of $900 \mathrm{kDa}$ and INCO without complexing proteins and a molecular weight $150 \mathrm{kDa}$ have a comparable spread..$^{22} \mathrm{In}$ addition, progenitor toxin size may be irrelevant with this regard as progenitor complexes are thought to dissociate in the vial on reconstitution with normal saline and under physiological conditions. ${ }^{27,28}$ Molecular weight and the presence of complexing proteins do not seem to affect spread or diffusion of the product. ${ }^{28}$

Complexing proteins are believed to aid in the uptake and transcytosis of BoNT through the intestinal epithelium (protection from gastric $\mathrm{pH}$ extremes, resistance against stomach and intestinal proteases, and transportation across the intestinal epithelium) when ingested orally. ${ }^{105,106}$ However, in cosmetic and therapeutic setting where BoNT is not taken orally, the mentioned functions of the complexing proteins are not relevant to clinical efficacy. ${ }^{30}$

A few studies have reported that both ONA and INCO have comparable spread. ${ }^{22}$ Hexsel et al reported that similar action halos (muscular and sweat gland activity) were observed with standardized injections (equivalence ratio, same volume, depth, and technique) of ONA and ABO. However, $\mathrm{ABO}$ has been reported to have significantly greater spread than ONA/INCO. ${ }^{107,108}$

Several factors are thought to affect the potential for spread of BoNT, which include the following: ${ }^{27,109,110}$

- Clinical dose

- Solution

- Concentration

- Injection technique

- Type of target site

- Post-injection massage

- Location of injection within the muscle

- Level of muscle hyperactivity

- Depth of injection.

\section{Immunogenicity}

The ability of a protein product to elicit antibody formation is known as immunogenicity. Secondary nonresponse and primary nonresponse are different from immunogenicity (Table 4). BoNT preparations available commercially, excluding the excipient albumin, contain nonhuman proteins. These may act as antigens and elicit antibody formation when injected into a patient. ${ }^{111}$ Botulinum toxin

Table 4 Immunogenicity vs primary nonresponse vs secondary nonresponse

Immunogenicity, and primary and secondary nonresponse

Immunogenicity The ability of a protein product to elicit antibody formation

Primary Failure to respond to the first and any subsequent nonresponse administration

Secondary Initial response to treatment, loss of clinical nonresponse responsiveness over time with repeated treatments 
has the potential to induce an immune response, similar to other therapeutic proteins, and is regarded as foreign by the host. This is particularly true with repeated administration. Immunogenicity can result in development of neutralizing antibodies, which in turn may or may not result in secondary treatment failure. ${ }^{29}$ Antibodies can be produced against the $150 \mathrm{kDa}$ neurotoxin itself or the nontoxic complexing proteins (40-60\% of treated patients) or both. The antibodies produced against the nontoxic complexing proteins are non-neutralizing antibodies and do not affect the neurotoxin activity. When antibodies are produced against the neurotoxin itself, the pharmacological effect of the neurotoxin is blocked. The rate of secondary treatment failure could potentially be reduced using purified neurotoxin preparations (INCO). Inactivated or nonactivated neurotoxins influence antibody formation and increase the risk of formation of neutralizing antibodies. ${ }^{8}$

BoNT-A products have shown to exhibit lower clinically detectable levels of antibodies in comparison to other approved biological products. ${ }^{111}$ Antibodies that may develop as a result of BoNT administration are not likely to crossreact with endogenous proteins; however, it is possible that the therapeutic response is lost. ${ }^{111}$ Factors that impact the immunogenicity of BoNTs include the following: ${ }^{111}$

- Product-related factors

- Manufacturing process

- The three-dimensional structure of therapeutic proteins plays an important role in their clinical performance

$\circ$ Toxin source

$\circ$ Inactive toxin

- The $150 \mathrm{kDa}$ core BoNT of BoNT products is in an inactive form and can be immunogenic

- The antigenic protein load

- The $150 \mathrm{kDa}$ core BoNT can stimulate the formation of neutralizing antibodies and is known as the antigenic protein load. The overall neurotoxin protein amount is not the same as the antigenic protein load and includes both the core neurotoxin and NAPs

- Accessory proteins and excipients

- Treatment-related factors

- Dose: the overall toxin dose

- Treatment intervals/booster injections

- The risk for neutralizing antibody formation and nonresponse may increase with shorter treatment intervals of less than 2 months apart
○ Prior exposure

- The immune response to botulinum toxin products may be influenced by previous exposures.

\section{Storage}

ONA and ABO need to be stored under special temperatures, and this is critical. INCO can be stored at room temperature. ${ }^{20}$ The manufacturers for the products recommend optimal storage condition for their products. The manufacturers recommend that BoNT-A should only be used within the first 4 hours after reconstitution of $\mathrm{ONA}^{117,130}$ or within 1 hour after reconstitution of $\mathrm{ABO} .{ }^{113}$ The recommendation is for the reconstituted product to be kept at $2^{\circ} \mathrm{C}-8^{\circ} \mathrm{C}$ and administered within 24 hours after reconstitution. It also explains that the product should be used immediately considering a microbiological point of view. ${ }^{114}$

Studies have shown that there is no alteration in potency of ONA even when it is refrigerated or refrozen for up to 1 week $^{120}$ or for up to 2 weeks after reconstitution. ${ }^{116-118}$ Although warned about sterility issues, Park and Ahn reported no degradation of the potency of reconstituted ONA by refrigeration for 4 weeks. ${ }^{119,120}$ Hexsel et al reported that with correct sterile handling and storage under refrigeration, ONA within up to 6 weeks after reconstitution did not result in a significant alteration in the detectable clinical response from both patient's and the observer's point of view. ${ }^{121}$ Soares et al studied the efficacy of INCO after prolonged storage ( 7 days) at room temperature $\left(25^{\circ} \mathrm{C}\right)$ for treatment of dynamic lateral canthus lines. Their study was a randomized, doubleblinded, split-face study, and evaluation was carried out over a 4-month period. They reported that prolonged storage at room temperature did not significantly alter its efficacy or longevity. ${ }^{122}$

\section{Adverse effects}

The distant effect of BoNT is of concern as it can cause local or systemic adverse effects. Systemic adverse effects are due to the effect of BoNT on the tissues distant from the injection site and are due to transport within the blood. ${ }^{20}$

The associated adverse effects are generally of three types:

- Adverse effects related to expected effects of the BoNT, for example, excessive local muscle weakness

- Adverse effects due to the spread of the BoNT to the surrounding muscles that were not injected or the target

- Adverse effects due to systemic distribution of the toxin. ${ }^{125}$ 
An increased frequency of local adverse effects with $\mathrm{ABO}$ compared to ONA has been reported when used for treating cervical dystonia. ${ }^{126}$ Although the reason for this is unclear, this could be due to increased spread as demonstrated by animal studies or incorrect conversion factors. ${ }^{20}$

The most effective dose at the smallest volume will achieve maximal dose response and minimal side effects. This means for targeted treatment, small volumes and high doses are effective and superior to large injection volume and low dose. The combination of small volume and high dose localizes the toxin, in addition to containing the biological effect of the toxin (muscle paralysis). ${ }^{1,127}$ Large volume and low dose weaken the muscle and may not result in complete muscle paralysis, resulting in an overall smoothing effect with an associated risk of toxin spread to adjacent untargeted muscles. ${ }^{128,129}$

\section{Conclusion}

Botulinum toxin products are used for therapeutic and cosmetic purposes, and their injections have been reported as the most popular noninvasive cosmetic procedure requested and carried out. The popularity of BoNT as a therapeutic and aesthetic agent is due to its potency, neurospecificity, efficacy, safety, complete reversibility, and a low rate of antibody formation. BoNT blocks presynaptic acetylcholine release resulting in reduced or diminished muscle contraction. It is used to temporarily treat wrinkles that are the result of muscle contraction and normal facial movement. This results in temporary improvement in the appearance of the areas affected by lines and wrinkles, for facial contouring, reducing sweating, and improving the skin. The different products available in the market vary in terms of units, chemical properties, biological activities, and weight and hence are not interchangeable. The products' manufacturing process is different. Manufacturing process and conditions such as $\mathrm{pH}$, temperature, formulation, and concentration are extremely crucial. Alterations in these process and conditions can increase the likelihood of formation of inactivated toxoid proteins, which in turn may be immunogenic. For safe clinical practice, and to achieve optimal results, the practitioners need to understand the clinical issues of potency, conversion ratio, and safety issues (toxin spread and immunogenicity). All three FDA-approved and popular preparations (ONA, INCO, ABO) are similar. The efficacy of ONA is comparable, and ONA and INCO have a 1:1 conversion ratio. These products are reported to have therapeutic equivalence in different indications. The conversation ratio of $\mathrm{ABO}$ is different from the other two preparations. The ratio is reported to be approximately $1: 2.5$. It is important to keep in mind that these products are not interchangeable. To reduce and minimize potential antibody resistance, the smallest effective dose should be used, treatment intervals should be less than 2-3 months, and booster injections should be avoided. The key factors affecting the clinical response to BoNT injections are individual anatomy, toxin preparation, dose-response relationship, reconstitution, length of storage after reconstitution, and immunogenicity. Injection patterns, techniques, dilutions, diffusion, and injection volumes of a particular formulation of BoNT are not interchangeable with other formulations. Understanding of clinical pharmacology of BoNT-A therapy will be useful for standardizing techniques used and achieving consistent and optimal therapeutic results. In addition, products and procedures must be selected and prescribed according to individual needs and aims of treatment.

\section{Disclosure}

The authors report no conflicts of interest in this work.

\section{References}

1. Huang W, Foster JA, Rogachefsky AS. Pharmacology of botulinum toxin. J Am Acad Dermatol. 2000;43(2):249-259.

2. Rossetto O, Pirazzini M, Montecucco C. Botulinum neurotoxins: genetic, structural and mechanistic insights. Nat Rev Microbiol. 2014;12(8):535-549.

3. Scaglione F. Conversion ratio between Botox ${ }^{\circledR}$, Dysport ${ }^{\circledR}$, and Xeo$\min { }^{\circledR}$ in clinical practice. Toxins (Basel). 2016;8(3).

4. Coffield JA, Bakry N, Zhang RD, Carlson J, Gomella LG, Simpson LL. In vitro characterization of botulinum toxin types A, C and D action on human tissues: combined electrophysiologic, pharmacologic and molecular biologic approaches. J Pharmacol Exp Ther. 1997;280(3):1489-1498.

5. Eleopra R, Tugnoli V, Quatrale R, Rossetto O, Montecucco C. Different types of botulinum toxin in humans. Mov Disord. 2004;19 Suppl 8:S53-S59.

6. Eleopra R, Tugnoli V, Quatrale R, Rossetto O, Montecucco C, Dressler D. Clinical use of non-A botulinum toxins: botulinum toxin type $\mathrm{C}$ and botulinum toxin type F. Neurotox Res. 2006;9(2-3):127-131.

7. Pirazzini M, Rossetto O, Eleopra R, Montecucco C. Botulinum neurotoxins: biology, pharmacology, and toxicology. Pharmacol Rev. 2017;69(2):200-235.

8. Boone B. Botulinum Toxin in Aesthetic Medicine. European Handbook of Dermatological Treatments. Springer Berlin Heidelberg: 2015:1089-1106.

9. Aoki KR, Guyer B. Botulinum toxin type A and other botulinum toxin serotypes: a comparative review of biochemical and pharmacological actions. Eur J Neurol. 2001;8 Suppl 5:21-29.

10. Montecucco C, Molgó J. Botulinal neurotoxins: revival of an old killer. Curr Opin Pharmacol. 2005;5(3):274-279.

11. Dressler D, Saberi FA, Barbosa ER. Botulinum toxin: mechanisms of action. Arq Neuropsiquiatr. 2005;63(1):180-185.

12. de Paiva A, Meunier FA, Molgó J, Aoki KR, Dolly JO. Functional repair of motor endplates after botulinum neurotoxin type A poisoning: biphasic switch of synaptic activity between nerve sprouts and their parent terminals. Proc Natl Acad Sci U S A. 1999;96(6):3200-3205.

13. Rogozhin AA, Pang KK, Bukharaeva E, Young C, Slater CR. Recovery of mouse neuromuscular junctions from single and repeated injections of botulinum neurotoxin A. J Physiol. 2008;586(13):3163-3182. 
14. Matarasso SL. Comparison of botulinum toxin types A and B: a bilateral and double-blind randomized evaluation in the treatment of canthal rhytides. Dermatol Surg. 2003;29(1):7-13; discussion 13.

15. Wilson AJ, Chang B, Taglienti AJ, et al. A quantitative analysis of OnabotulinumtoxinA, AbobotulinumtoxinA, and IncobotulinumtoxinA: a randomized, double-blind, prospective clinical trial of comparative dynamic strain reduction. Plast Reconstr Surg. 2016;137(5):1424-1433.

16. Rosales RL, Bigalke H, Dressler D. Pharmacology of botulinum toxin: differences between type A preparations. Eur J Neurol. 2006;13 Suppl $1: 2-10$.

17. Swaminathan S, Eswaramoorthy S. Structural analysis of the catalytic and binding sites of Clostridium botulinum neurotoxin B. Nat Struct Biol. 2000;7(8):693-699.

18. Montal M. Botulinum neurotoxin: a marvel of protein design. Annu Rev Biochem. 2010;79:591-617.

19. Rossetto O, Morbiato L, Caccin P, Rigoni M, Montecucco C. Presynaptic enzymatic neurotoxins. J Neurochem. 2006;97(6):1534-1545.

20. Dressler D, Benecke R. Pharmacology of therapeutic botulinum toxin preparations. Disabil Rehabil. 2007;29(23):1761-1768.

21. Frevert J. Content of botulinum neurotoxin in botox $₫ /$ vistabel $\AA$, dysport $\AA /$ azzalure $\AA$, and xeomin $\AA /$ bocouture $\AA$. Drugs $R D$. 2010;10(2):67-73.

22. Kerscher M, Roll S, Becker A, Wigger-Alberti W. Comparison of the spread of three botulinum toxin type A preparations. Arch Dermatol Res. 2012;304(2):155-161.

23. Pickett A. Consistent biochemical data are essential for comparability of botulinum toxin type A products. Drugs R D. 2011;11(1):97-98; author reply 98-99.

24. Fang PK, Raphael BH, Maslanka SE, Cai S, Singh BR. Analysis of genomic differences among Clostridium botulinum type A1 strains. BMC Genomics. 2010;11:725.

25. Panjwani N, O'Keeffe R, Pickett A. Biochemical, functional and potency characteristics of type A botulinum toxin in clinical use. Botulinum J. 2008;1(1):153-166.

26. Schantz EJ, Johnson EA. Properties and use of botulinum toxin and other microbial neurotoxins in medicine. Microbiol Rev. 1992;56(1):80-99.

27. Pickett A. Dysport: pharmacological properties and factors that influence toxin action. Toxicon. 2009;54(5):683-689.

28. Eisele KH, Fink K, Vey M, Taylor HV. Studies on the dissociation of botulinum neurotoxin type A complexes. Toxicon. 2011;57(4):555-565.

29. Frevert J. Pharmaceutical, biological, and clinical properties of botulinum neurotoxin type A products. Drugs $R$ D. 2015;15(1):1-9.

30. Frevert J, Dressler D. Complexing proteins in botulinum toxin type A drugs: a help or a hindrance? Biologics. 2010;4:325-332.

31. Rummel A. The long journey of botulinum neurotoxins into the synapse. Toxicon. 2015;107(Pt A):9-24.

32. Wheeler A, Smith HS. Botulinum toxins: mechanisms of action, antinociception and clinical applications. Toxicology. 2013;306:124-146.

33. Foran PG, Mohammed N, Lisk GO, et al. Evaluation of the therapeutic usefulness of botulinum neurotoxin $\mathrm{B}, \mathrm{C} 1, \mathrm{E}$, and $\mathrm{F}$ compared with the long lasting type A. Basis for distinct durations of inhibition of exocytosis in central neurons. J Biol Chem. 2003;278(2):1363-1371.

34. Shaari CM, Sanders I. Quantifying how location and dose of botulinum toxin injections affect muscle paralysis. Muscle Nerve. 1993;16(9):964-969.

35. Antonucci F, Rossi C, Gianfranceschi L, Rossetto O, Caleo M. Longdistance retrograde effects of botulinum neurotoxin A. J Neurosci. 2008;28(14):3689-3696.

36. Matak I, Bach-Rojecky L, Filipović B, Lacković Z. Behavioral and immunohistochemical evidence for central antinociceptive activity of botulinum toxin A. Neuroscience. 2011;186:201-207.

37. Matak I, Riederer P, Lacković Z. Botulinum toxin's axonal transport from periphery to the spinal cord. Neurochem Int. 2012;61(2): 236-239.

38. Restani L, Antonucci F, Gianfranceschi L, Rossi C, Rossetto O, Caleo M. Evidence for anterograde transport and transcytosis of botulinum neurotoxin A (BoNT/A). J Neurosci. 2011;31(44):15650-15659.
39. Mazzocchio R, Caleo M. More than at the neuromuscular synapse: actions of botulinum neurotoxin $\mathrm{A}$ in the central nervous system. Neuroscientist. 2015;21(1):44-61.

40. Matak I, Lacković Z. Botulinum toxin A, brain and pain. Prog Neurobiol. 2014;119-120:39-59.

41. Lee HH, Kim ST, Lee KJ, Baik HS. Effect of a second injection of botulinum toxin on lower facial contouring, as evaluated using 3-dimensional laser scanning. Dermatol Surg. 2015;41(4):439-444.

42. Keaney TC, Alster TS. Botulinum toxin in men: review of relevant anatomy and clinical trial data. Dermatol Surg. 2013;39(10): 1434-1443.

43. Carruthers A, Carruthers J. Prospective, double-blind, randomized, parallel-group, dose-ranging study of botulinum toxin type A in men with glabellar rhytids. Dermatol Surg. 2005;31(10):1297-1303.

44. Nestor M, Ablon G, Pickett A. Key parameters for the use of abobotulinumtoxinA in aesthetics: onset and duration. Aesthet Surg J. 2017;37(supp1_1):S20-S31.

45. Hallett M. Explanation of timing of botulinum neurotoxin effects, onset and duration, and clinical ways of influencing them. Toxicon. 2015;107(Pt A):64-67.

46. Simpson LL. Identification of the major steps in botulinum toxin action. Annu Rev Pharmacol Toxicol. 2004;44:167-193.

47. Hankins CL, Strimling R, Rogers GS. Botulinum A toxin for glabellar wrinkles. Dermatol Surg. 1998;24(11):1181-1183.

48. Flynn TC. Botulinum toxin. Am J Clin Dermatol. 2010;11(3):183-199.

49. Carruthers A, Carruthers J, Lowe NJ, et al. One-year, randomised, multicenter, two-period study of the safety and efficacy of repeated treatments with botulinum toxin type A in patients with glabellar lines. J Drug Assess. 2004;7(2):63-86.

50. Michaels BM, Csank GA, Ryb GE, Eko FN, Rubin A. Prospective randomized comparison of onabotulinumtoxinA (Botox) and abobotulinumtoxinA (Dysport) in the treatment of forehead, glabellar, and periorbital wrinkles. Aesthet Surg J. 2012;32(1):96-102.

51. Small R. Botulinum toxin injection for facial wrinkles. Am Fam Physician. 2014;90(3):168-175.

52. Dolly JO, Aoki KR. The structure and mode of action of different botulinum toxins. Eur J Neurol. 2006;13 Suppl 4:1-9.

53. Rappl T, Parvizi D, Friedl H, et al. Onset and duration of effect of incobotulinumtoxinA, onabotulinumtoxinA, and abobotulinumtoxinA in the treatment of glabellar frown lines: a randomized, double-blind study. Clin Cosmet Investig Dermatol. 2013;6:211-219.

54. Glogau R, Kane M, Beddingfield F, et al. OnabotulinumtoxinA: a meta-analysis of duration of effect in the treatment of glabellar lines. Dermatol Surg. 2012;38(11):1794-1803.

55. Dressler D, Rothwell JC. Electromyographic quantification of the paralysing effect of botulinum toxin in the sternocleidomastoid muscle. Eur Neurol. 2000;43(1):13-16.

56. Poewe W, Deuschl G, Nebe A, et al. What is the optimal dose of botulinum toxin A in the treatment of cervical dystonia? Results of a double blind, placebo controlled, dose ranging study using Dysport. German Dystonia Study Group. J Neurol Neurosurg Psychiatry. 1998;64(1):13-17.

57. Flynn TC. Botulinum toxin: examining duration of effect in facial aesthetic applications. Am J Clin Dermatol. 2010;11(3):183-199.

58. Carruthers A, Carruthers J, Said S. Dose-ranging study of botulinum toxin type A in the treatment of glabellar rhytids in females. Dermatol Surg. 2005;31(4):414-422; discussion 422.

59. Kim NH, Chung JH, Park RH, Park JB. The use of botulinum toxin type A in aesthetic mandibular contouring. Plast Reconstr Surg. 2005;115(3):919-930.

60. Park MY, Ahn KY, Jung DS. Botulinum toxin type A treatment for contouring of the lower face. Dermatol Surg. 2003;29(5):477-483; discussion 483

61. Ahn J, Horn C, Blitzer A. Botulinum toxin for masseter reduction in Asian patients. Arch Facial Plast Surg. 2004;6(3):188-191.

62. Smyth AG. Botulinum toxin treatment of bilateral masseteric hypertrophy. Br J Oral Maxillofac Surg. 1994;32(1):29-33.

63. Guyuron B, Rose K, Kriegler JS, Tucker T. Hourglass deformity after botulinum toxin type A injection. Headache. 2004;44(3):262-264. 
64. Sesardic D, Das RG. Alternatives to the LD50 assay for botulinum toxin potency testing: strategies and progress towards refinement, reduction and replacement. Proc. 6th World Congress on Alternatives and Animal Use in the Life Sciences, Tokyo, Japan, 21-25 August 2007. AATEX. 2007;14(Special Issue):581-585.

65. Fernández-Salas E, Wang J, Molina Y, Nelson JB, Jacky BP, Aoki KR. Botulinum neurotoxin serotype A specific cell-based potency assay to replace the mouse bioassay. PLoS One. 2012;7(11):e49516.

66. Business Wire. Allergan receives FDA approval for first-of-its-kind, fully in vitro, cell-based assay for BOTOX $®$ and BOTOX $®$ cosmetic (onabotulinumtoxinA). 2011. Available from: http://www.businesswire.com/news/home/20110624005918/en/Allergan-ReceivesFDA-Approval-First-of-Its-Kind-Fully-vitro. Accessed February 2018.

67. Adler S, Bicker G, Bigalke H, et al. The current scientific and legal status of alternative methods to the LD50 test for botulinum neurotoxin potency testing. The report and recommendations of a ZEBET Expert Meeting. Altern Lab Anim. 2010;38(4):315-330.

68. Hambleton P, Pickett AM. Potency equivalence of botulinum toxin preparations. J R Soc Med. 1994;87(11):719.

69. Sesardic D. Is it possible to accurately determine content of botulinum neurotoxin type A in drug products? Drugs $R$ D. 2010;10(2): 91-92.

70. Hunt T, Clarke K. Potency evaluation of a formulated drug product containing 150-kd botulinum neurotoxin type A. Clin Neuropharmacol. 2009;32(1):28-31.

71. Carruthers JD, Carruthers JA. Treatment of glabellar frown lines with C. botulinum-A exotoxin. J Dermatol Surg Oncol. 1992;18(1):17-21.

72. Klein AW. Dilution and storage of botulinum toxin. Dermatol Surg. 1998;24(11):1179-1180.

73. Alam M, Dover JS, Arndt KA. Pain associated with injection of botulinum A exotoxin reconstituted using isotonic sodium chloride with and without preservative: a double-blind, randomized controlled trial. Arch Dermatol. 2002;138(4):510-514.

74. Kwiat DM, Bersani TA, Bersani A. Increased patient comfort utilizing botulinum toxin type A reconstituted with preserved versus nonpreserved saline. Ophthal Plast Reconstr Surg. 2004;20(3):186-189.

75. Sarifakioglu N, Sarifakioglu E. Evaluating effects of preservativecontaining saline solution on pain perception during botulinum toxin type-a injections at different locations: a prospective, single-blinded, randomized controlled trial. Aesthetic Plast Surg. 2005;29(2):113-115.

76. Trindade De Almeida AR, Kadunc BV, Di Chiacchio N, Neto DR. Foam during reconstitution does not affect the potency of botulinum toxin type A. Dermatol Surg. 2003;29(5):530-531; discussion 532.

77. Kazim NA, Black EH. Botox: shaken, not stirred. Ophthal Plast Reconstr Surg. 2008;24(1):10-12.

78. Carruthers J, Fagien S, Matarasso SL. Consensus recommendations on the use of botulinum toxin type A in facial aesthetics. Ophthal Plast Reconstr Surg. 2005;21(2):165.

79. Trindade De Almeida AR, Secco LC, Carruthers A. Handling botulinum toxins: an updated literature review. Dermatol Surg. 2011;37(11):1553-1565.

80. Carey WD. Incorrect reconstitution of incobotulinumtoxinA leads to loss of neurotoxin. J Drugs Dermatol. 2014;13(6):735-738.

81. Niamtu J 3rd. Neurotoxin waste from drawing product through the vial stopper. J Clin Aesthet Dermatol. 2014;7(6):33-37.

82. Flynn TC, Carruthers A, Carruthers J. Surgical pearl: the use of the Ultra-Fine II short needle 0.3 -cc insulin syringe for botulinum toxin injections. J Am Acad Dermatol. 2002;46(6):931-933.

83. Yanagihara M, Fujii T, Wakamatu N, Ishizaki H, Takehara T, Nawate K. Silicone granuloma on the entry points of acupuncture, venepuncture and surgical needles. J Cutan Pathol. 2000;27(6):301-305.

84. Baldwin RN. Contamination of insulin by silicone oil: a potential hazard of plastic insulin syringes. Diabet Med. 1988;5(8):789-790.

85. Tschetter AJ, Hochwalt PC, Colleran E, Stone MS. Silicone granulomas in the setting of acupuncture with silicone-coated needles. J Clin Investig Dermatol. 2014;2(1):2.
86. Dressler D, Mander G, Fink K. Measuring the potency labelling of onabotulinumtoxin $\mathrm{A}\left(\right.$ Botox $\left.{ }^{\circledR}\right)$ and incobotulinumtoxin $\mathrm{A}(\mathrm{Xeomin} \AA$ ) in an LD50 assay. J Neural Transm (Vienna). 2012;119(1):13-15.

87. Aoki KR, Ranoux D, Wissel J. Using translational medicine to understand clinical differences between botulinum toxin formulations. Eur J Neurol. 2006;13 Suppl 4:10-19.

88. Prager W, Wissmüller E, Kollhorst B, Williams S, Zschocke I. Comparison of two botulinum toxin type A preparations for treating crow's feet: a split-face, double-blind, proof-of-concept study. Dermatol Surg. 2010;36 Suppl 4:2155-2160.

89. Kane MA, Gold MH, Coleman WP 3rd, et al. A randomized, doubleblind trial to investigate the equivalence of IncobotulinumtoxinA and OnabotulinumtoxinA for glabellar frown lines. Dermatol Surg. 2015;41(11):1310-1319.

90. Marchetti A, Magar R, Findley L, et al. Retrospective evaluation of the dose of Dysport and BOTOX in the management of cervical dystonia and blepharospasm: the REAL DOSE study. Mov Disord. 2005;20(8):937-944.

91. Wohlfarth K, Göschel H, Frevert J, Dengler R, Bigalke H. Botulinum A toxins: units versus units. Naunyn Schmiedebergs Arch Pharmacol. 1997;355(3):335-340.

92. Ranoux D, Gury C, Fondarai J, Mas JL, Zuber M. Respective potencies of Botox and Dysport: a double blind, randomised, crossover study in cervical dystonia. JNeurol Neurosurg Psychiatry. 2002;72(4):459-462.

93. Yun JY, Kim JW, Kim HT, et al. Dysport and Botox at a ratio of 2.5:1 units in cervical dystonia: a double-blind, randomized study. Mov Disord. 2015;30(2):206-213.

94. De Boulle K, Fagien S, Sommer B, Glogau R. Treating glabellar lines with botulinum toxin type A-hemagglutinin complex: a review of the science, the clinical data, and patient satisfaction. Clin Interv Aging. 2010;5:101-118.

95. Aoki KR, Irvine R, Gallagher C. Re: Botox produces functional weakness in non-injected muscles adjacent to the target muscle. J Biomech. 2008;41(9):2066-2067.

96. Bentivoglio AR, Fasano A, Ialongo T, Soleti F, Lo Fermo S, Albanese A. Fifteen-year experience in treating blepharospasm with Botox or Dysport: same toxin, two drugs. Neurotox Res. 2009;15(3):224-231.

97. Cillino S, Raimondi G, Guépratte N, et al. Long-term efficacy of botulinum toxin A for treatment of blepharospasm, hemifacial spasm, and spastic entropion: a multicentre study using two drug-dose escalation indexes. Eye (Lond). 2010;24(4):600-607.

98. Jankovic J. Botulinum toxin therapy for cervical dystonia. Neurotox Res. 2006;9(2-3):145-148.

99. Lungu C, Karp BI, Alter K, Zolbrod R, Hallett M. Long-term followup of botulinum toxin therapy for focal hand dystonia: outcome at 10 years or more. Mov Disord. 2011;26(4):750-753.

100. Kane MA, Monheit G. The practical use of AbobotulinumtoxinA in aesthetics. Aesthet Surg J. 2017;37(Suppl_1):S12-S19.

101. Arezzo JC. NeuroBloc $₫ /$ Myobloc $\AA$ : unique features and findings. Toxicon. 2009;54(5):690-696.

102. Carruthers A, Carruthers J, Cohen J. Dilution volume of botulinum toxin type A for the treatment of glabellar rhytides: does it matter? Dermatol Surg. 2007;33(1 Spec No.):S97-S104.

103. Hsu TS, Dover JS, Arndt KA. Effect of volume and concentration on the diffusion of botulinum exotoxin A. Arch Dermatol. 2004;140(11): 1351-1354.

104. Ramirez-Castaneda J, Jankovic J, Comella C, Dashtipour K, Fernandez $\mathrm{HH}$, Mari Z. Diffusion, spread, and migration of botulinum toxin. Mov Disord. 2013;28(13):1775-1783.

105. Jin Y, Takegahara Y, Sugawara Y, Matsumura T, Fujinaga Y. Disruption of the epithelial barrier by botulinum haemagglutinin (HA) proteins differences in cell tropism and the mechanism of action between HA proteins of types A or B, and HA proteins of type C. Microbiology. 2009;155(Pt 1):35-45.

106. Fujinaga Y. Transport of bacterial toxins into target cells: pathways followed by cholera toxin and botulinum progenitor toxin. J Biochem. 2006;140(2):155-160. 
107. Hexsel D, Brum C, do Prado DZ. Field effect of two commercial preparations of botulinum toxin type A: a prospective, double-blind, randomized clinical trial. J Am Acad Dermatol. 2012;67(2):226-232.

108. Trindade de Almeida AR, Marques E, de Almeida J, Cunha T, Boraso R. Pilot study comparing the diffusion of two formulations of botulinum toxin type A in patients with forehead hyperhidrosis. Dermatol Surg. 2007;33(1 Spec No.):S37-S43.

109. Brodsky MA, Swope DM, Grimes D. Diffusion of botulinum toxins. Tremor Other Hyperkinet Mov (N Y). 2012;2:tre-02-85-417-1.

110. Roche N, Schnitzler A, Genêt FF, Durand MC, Bensmail D. Undesirable distant effects following botulinum toxin type a injection. Clin Neuropharmacol. 2008;31(5):272-280.

111. Naumann M, Boo LM, Ackerman AH, Gallagher CJ. Immunogenicity of botulinum toxins. JNeural Transm (Vienna). 2013;120(2):275-290.

112. BOTOX ${ }^{\circledR}$ [package insert]. Irvine, CA: Allergan, Inc.; 2002.

113. Dysport ${ }^{\circledR}$ [package insert]. Maidenhead: Ipsen Products; 2002.

114. Package leaflet: Information for the user - BOCOUTURE 50 units powder for solution for injection. 2016.

115. Markey AC. Botulinum A exotoxin in cosmetic dermatology. Clin Exp Dermatol. 2000;25(3):173-175.

116. Sloop RR, Cole BA, Escutin RO. Reconstituted botulinum toxin type A does not lose potency in humans if it is refrozen or refrigerated for 2 weeks before use. Neurology. 1997;48(1):249-253.

117. Frankel AS. Botox for rejuvenation of the periorbital region. Facial Plast Surg. 1999;15(3):255-262.

118. Carruthers A, Carruthers J. Toxins 99, new information about the botulinum neurotoxins. Dermatol Surg. 2000;26(3):174-176.

119. Park MY, Ahn KY. Effect of the refrigerator storage time on the potency of botox for human extensor digitorum brevis muscle paralysis. J Clin Neurol. 2013;9(3):157-164.

120. Yang GC, Chiu RJ, Gillman GS. Questioning the need to use Botox within 4 hours of reconstitution: a study of fresh vs 2-week-old Botox. Arch Facial Plast Surg. 2008;10(4):273-279.
121. Hexsel DM, De Almeida AT, Rutowitsch M, et al. Multicenter, doubleblind study of the efficacy of injections with botulinum toxin type A reconstituted up to six consecutive weeks before application. Dermatol Surg. 2003;29(5):523-529.

122. Soares DJ, Dejoseph LM, Zuliani GF, Liebertz DJ, Patel VS. Impact of postreconstitution room temperature storage on the efficacy of incobotulinumtoxinA treatment of dynamic lateral canthus lines. Dermatol Surg. 2015;41(6):712-717.

123. DYSPORT $®$ (abobotulinumtoxin $A$ ) for injection [prescribing information]. Basking Ridge, NJ: Ipsen Biopharmaceuticals, Inc; 2017.

124. MEDICATION GUIDE, BOTOX $®$ BOTOX $®$, Cosmetic (Boe-tox), (onabotulinumtoxinA) for Injection. Available from: https:/www.allergan.com/miscellaneous-pages/allergan-pdf-files/botox_med_guide. Accessed February 2018.

125. Foster KA, Bigalke H, Aoki KR. Botulinum neurotoxin - from laboratory to bedside. Neurotox Res. 2006;9(2-3):133-140.

126. Dressler D. Dysport produces intrinsically more swallowing problems than Botox: unexpected results from a conversion factor study in cervical dystonia. J Neurol Neurosurg Psychiatry. 2002;73(5):604; author reply 604.

127. Borodic GE, Pearce LB, Smith K, Joseph M. Botulinum a toxin for spasmodic torticollis: multiple vs single injection points per muscle. Head Neck. 1992;14(1):33-37.

128. Garcia A, Fulton JE Jr. Cosmetic denervation of the muscles of facial expression with botulinum toxin. A dose-response study. Dermatol Surg. 1996;22(1):39-43

129. Edelstein C, Shorr N, Jacobs J, Balch K, Goldberg R. Oculoplastic experience with the cosmetic use of botulinum A exotoxin. Dermatol Surg. 1998;24(11):1208-1212.

130. Highlights of prescribing information, BOTOX Cosmetic (onabotulinumtoxinA) for injection, for intramuscular use, Initial U.S. Approval: 1989. Revised 10/2017 [cited 2018; Available from: https://www. allergan.com/assets/pdf/botox_cosmetic_pi.pdf.
Clinical, Cosmetic and Investigational Dermatology

\section{Publish your work in this journal}

Clinical, Cosmetic and Investigational Dermatology is an international, peer-reviewed, open access, online journal that focuses on the latest clinical and experimental research in all aspects of skin disease and cosmetic interventions. This journal is included on PubMed. The manuscript management system is completely online
Dovepress

and includes a very quick and fair peer-review system, which is all easy to use. Visit http://www.dovepress.com/testimonials.php to read real quotes from published authors 